\title{
SIGNOS DO DESIGN DE INTERIORES: INTERFACES ENTRE USO, CONSUMO E
} ARTE

\section{Sings of interior designs: interfaces between use, consumption and art}

\author{
Miquelina Cavalcante ${ }^{1}$ \\ Rossana Gaia ${ }^{2}$ \\ Patrícia Lins ${ }^{3}$ \\ Áurea Rapôso ${ }^{4}$
}

\section{Resumo}

Este trabalho analisa o design de interiores como uma das mais vigorosas formas de comunicação da contemporaneidade, através da relação homem-objetos ambientes e homemobjetos do desejo. Aborda as interações perceptivas e cognitivas relacionadas aos objetos de uso e/ou de desejo. Discute a importância do design dos objetos e seus significados, vinculando-a ao processo de industrialização, ao consumo e ao diferencial do produto enquanto signo que personifica. Aqui, também discutido enquanto objeto de luxo. O desejo do consumo, no momento atual de crise econômica global, requer ainda refletir sobre a sustentabilidade do planeta e o compromisso dos profissionais deste campo.

Palavras-chave: design, globalização, sustentabilidade.

\begin{abstract}
This article analyzes interior designs as one of the most vigorous contemporaneous mean of communication, amongst its relation between man/object/environment and man and desired object of personal use and/or desire. It approaches the perspective and cognitive interactions related to the objects of personal use and/or desire. It discusses the importance of the design

\footnotetext{
${ }^{1}$ Arquiteta e Urbanista, Mestre em Arquitetura e Urbanismo (UFAL), especialista em Design Estratégico (CESMAC), coordenadora de Design do Instituto Federal de Educação, Ciência e Tecnologia de Alagoas (IFAL), professora dos cursos de design dessa instituição e pesquisadora do Grupo de Pesquisa Design e Estudos Interdisciplinares. Contato: miquelinac@ yahoo.com.br.

${ }^{2}$ Jornalista, Dr ${ }^{a}$. em Linguística (UFAL), Mestre em Educação (UFPB), especialista em Literatura Brasileira (UFAL), professora do Instituto Federal de Educação, Ciência e Tecnologia de Alagoas (IFAL) na Coordenadoria de Design, líder do Grupo de Pesquisa Design e Estudos Interdisciplinares, membro da Sociedade Brasileira de Estudos Interdisciplinares da Comunicação (INTERCOM). Contato: rogaia @ uol.com.br.

${ }^{3}$ Arquiteta e Urbanista, Mestre em Engenharia de Produção (UFPB), professora do IFAL na Coordenadoria de Design, pesquisadora do Grupo de Pesquisa Design e Estudos Interdisciplinares (CNPq/IFAL). Contato: patriciasoares.lins@yahoo.com.br.

${ }^{4}$ Arquiteta e Urbanista, Mestre em Desenvolvimento e Meio Ambiente (UFAL), especialista em Iluminação e Design de Interiores (UCB-RJ), professora do Instituto Federal de Alagoas (IFAL) na Coordenadoria de Design, líder do Grupo de Pesquisa Design e Estudos Interdisciplinares (CNPq/IFAL) e pesquisadora dos Grupos de Pesquisa Design Social e Ecodesign (CNPq/INT-RJ). Contato: aurearaposo@ig.com.br.
} 
and their meanings integrating to the industrialization process, to the consumption and to the differential that the product holds. Discussed here with as a Luxury item, the willingness to acquire something at this moment of global economic crisis requires a more serious reflexion about the planet's sustainability and the professionals on this field's deeper compromise.

Key-words: design, globalization, sustainability

\section{Resumen}

Este trabajo analiza el diseño de interiores como una de las más vigorosas formas de la comunicación contemporánea, a través de la relación hombre-objetos ambientes y hombreobjetos del deseo. Aborda las interacciones perceptivas y cognitivas relacionadas a los objetos de utilidad y/o de deseo. Debate la importancia del diseño de los objetos y sus sentidos, vinculase al proceso de industrialización, en el consumo y al diferencial del producto mientras signo que personifica. Aquí, también demostrado como objeto de lujo. El deseo de consumo, en el actual momento de crisis económica mundial obliga aún a pensar en la sostenibilidad del planeta y exige el compromiso de los profesionales en este campo.

Palabras-clave: diseño, globalización, sostenibilidad

\section{INTRODUÇÃO}

O design, como produção de uma realidade inexistente, tem como base o processo de pensamento contínuo e não instrumental, representação de narrativas, resultado de escolhas. Liga-se à percepção de uma necessidade de consumo, desejo de aquisição do objeto transformado em signo e que comunica o ser psicológico e o desejo do ser. Bürdek (2006, p. 11) destaca que o design está pulverizado em todas as experiências humanas: trabalho, lazer, educação, saúde, esporte, transporte, em suma, em ambientes públicos e privados, uma vez que tudo é fruto de configuração de forma consciente ou inconsciente. Próximo à pele, no caso do design de moda, ou afastado, como o design para uso espacial, os produtos comunicam, assim como definem grupos sociais.

Entendemos o design como uma das mais vigorosas formas de comunicação humana, porque, conforme nos ensina Flusser (2007, p. 90), há na comunicação humana um caráter inexoravelmente "artificial" e asseguramos, com base nas reflexões filosóficas propiciadas pelo autor, que o espaço habitado traduz um modo de ser próprio de um sujeito e/ou de uma época, a partir da construção de significados. Se a comunicação é a base do sentido da vida e 
da condição humana, consideramos o ambiente interno das residências, a mais peculiar - e por isso mesmo poderosa - forma de traduzir suas emoções e sensações. Mesmo que estejamos tentados a pensar em comunicação como formas linguísticas ou gestuais, argumentamos que a construção de marcas simbólicas como o ambiente habitável funciona como um dos artifícios da comunicação humana que expressa parte da identidade do sujeito, ainda que pelo viés do inconsciente, porque precisamos criar significados.

O designer de interiores está apto a planejar interferências, de qualquer natureza de uso e significação, para adequar as necessidades do usuário e melhorar a relação do homem com o espaço no circuito produção-consumo-produção, de forma a produzir uma realidade que antes não existia. Bigal (2001, p. 82) também define design como sintaxe e como "movimento do pensamento como experiência cognitiva na apreensão de algo que ainda não é signo, mas quer ser". Podemos ainda acrescentar, a partir de Key (2009), que o designer codifica e decodifica para um usuário ou para um grupo de usuários, seja através de um objeto, seja a partir da projeção de um ambiente, a tradução de uma metáfora, já que os sujeitos possuem a necessidade de perceber informações explícitas e implícitas e, a partir delas, construir significados.

Flusser (2007) recorre ao conceito de design enquanto algo que comunica, já que todo artefato, sendo matéria transformada, tem uma intenção. As observações de Flusser nos permitem indicar que é através da codificação do mundo que criamos versões alternativas da realidade, mundos paralelos nos quais o artefato se liga à possibilidade de uso e tem como consequência um modelo e uma informação. $\mathrm{O}$ design informa algo, para um determinado objetivo, para um ser em um determinado local e tempo. A forma somada à função reproduz um significado. $\mathrm{O}$ significado percebido associa-se novamente à forma e se transforma em signo.

A percepção é parte inerente dos próprios artefatos que podem ser úteis tanto ao consumo das necessidades, como para atender ao desejo de poder, através da ostentação. Santos (2005) indica que, através da produção de artefatos, os seres humanos materializam práticas sociais e valores culturais em cada momento histórico; estes podem ser resignificados dependendo de como ocorra sua apropriação pelas pessoas.

$\mathrm{Na}$ lógica do consumo, os artefatos possuem significados múltiplos e passíveis de transformações. O designer trata da configuração de produtos que mediam relações sociais do ponto de vista funcional e comunicativo e nisto consiste seu papel social. Projetar está 
inserido no campo de produção cultural e se relaciona aos costumes e crenças de grupos sociais, a um contexto de uso e a relações de mútua influência (Santos, 2005).

Móveis e objetos personificam as relações humanas, povoam o espaço que essas relações dividem entre si e podem ou não se revestir de uma alma; aqui, entendida como um significado. Baudrillard (1993, p. 22) salienta que

aquilo que faz a profundidade das casas de infância, sua pregnância na lembrança, é evidentemente esta estrutura complexa de interioridade onde os objetos despenteiam diante de nossos olhos os limites de uma configuração simbólica chamada residência.

Quando investiga o sistema social dos objetos, Baudrillard (1993) entende que "o objeto é fundamentalmente antropomórfico" e associa a ligação entre homem e objetos ambientes à mesma intimidade visceral estabelecida com o seu corpo, respeitadas às devidas proporções da analogia estabelecida. Acrescenta que os objetos encarnam no espaço laços afetivos que asseguram a sua permanência, até que uma nova ou mais moderna geração de objetos afaste-os, dispense-os ou ainda os reinstaure em uma realidade nostálgica de velhos e ou antigos objetos. Para o autor, a ligação entre homem e objetos ambientes ocorre de duas formas (inversas entre si): a primeira, quando é utilizado; e a segunda, quando é possuído. Nessa última, o objeto, abstraído da sua função de uso, assume um novo status subjetivo: a de objeto de desejo.

Os objetos de desejo inseridos nos interiores, também podem ser percebidos a partir do conceito de Zevi (1978, p. 18): "espaço que não pode ser representado perfeitamente de forma alguma, que não pode ser conhecido e vivido a não ser por experiência direta [...]”. Esse protagonismo do espaço interior nos motiva a repensar o uso dos mais diversos tipos de objetos, dentre eles os objetos de design e obras de arte, como fator relevante no processo perceptivo de nossa cultura, de nossos signos de consumo.

A noção de beleza para espaço interno, segundo Zevi (1978, p. 18), é resumida na atração, ou seja, no que "nos eleva e subjuga espiritualmente", enquanto feio é aquele espaço interior que nos aborrece e nos repele. A polêmica afirmação requer pensar o contexto econômico-social que o sujeito vivencia; a história de vida e a significação do espaço em um determinado contex to cultural.

O designer pode identificar uma série de discursos presentes nos objetos, pois os produtos nos "contam" como foram constituídos, a tecnologia empregada, o contexto cultural de origem, quem são seus usuários, suas formas de vida, seus grupos sociais e valores, em suma: relatam nossos desejos. Desta forma, Bürdek (2006) diferencia objetos de 
uso dos objetos simbólicos. Os primeiros são aqueles que cumprem uma tarefa básica e os segundos são aqueles que servem para significar, como obras de arte, a exemplo do espremedor de cítricos de Starck.

Defendemos que ambientes internos, a partir dos objetos que os configuram, geram significados, ainda que não explícitos. Os projetos dos designers de interiores estão inseridos nas relações do usuário com esses objetos. Bürdek (2006, p. 239) entende o design como "visualização de inovações"; para ele, a "competência de configuração" significa mais do que imprimir forma a objetos, traz em si temas como "comunicação, criatividade, soluções de segunda ordem, cooperação, criação de valor, transformação, progresso, globalização, polaridade ou sinergia". Em outras palavras, o design está intrinsecamente ligado aos processos múltiplos e sensoriais de percepção, de forma que homem, espaço, objetos e significados se partilham.

\section{DESIGN NA CONTEMPORANEIDADE: QUESTÕES PARA UM CONSUMO GLOBAL}

O design de interiores é uma das formas mais vigorosas de comunicação que o ser humano preserva ao longo dos séculos. Bürdek (2006) não somente destaca o aspecto comunicativo do design como também o enfatiza como meta-linguagem. No Brasil, podemos enfatizar o quanto a palavra design, por sua origem inglesa e seu estranhamento na língua portuguesa, constrói o sentido de charme, luxo e distinção. O Dicionário Oxford introduz o verbete design pela primeira vez em 1588, traduzido como: "Um plano desenvolvido pelo homem ou um esquema que possa ser realizado" (Bürdek, 2006, p. 13).

Do ponto de vista ideológico e cultural, a ideia de "charme" do design muito mais do que traduzir idiossincrasias do sujeito, reflete a hegemonia do "gosto" de uma época. Baudrillard (1993) reforça essa concepção em sua definição de “estilo" e exemplifica, comparando as mesas de campo do século XVIII à mesa Luís XV.

Hoje em dia as mesas de campo têm valor cultural — há trinta anos ainda valiam somente pelos serviços que podiam prestar. Não há relação no século XVIII entre a mesa "Luís XV" e a campesina: um fosso separa as duas categorias de objetos como as duas classes sociais a que pertencem. Nenhum sistema cultural as integra. Não se pode tampouco dizer que a mesa Luís XIII seja o modelo da qual as inumeráveis mesas e assentos que em seguida a imitaram vêm a ser a série. (...). A categoria social atribui aos objetos seu estatuto: se é nobre ou não, o nobre não é o termo privilegiado de uma série social, sua nobreza é uma graça que o distingue absolutamente. O equivalente para os objetos desta concepção transcendente é o que chamamos de "estilo" (BAUDRILLARD, 1993, p.145). 
O que em parte está em jogo aqui é a percepção de valor do objeto pré-industrial ao objeto-modelo industrial, cujo design - enquanto técnica, método, solução, mas também combinação plástico-material a valores socioculturais — os diferencia, caracteriza-os e lhes agrega um valor único. O objeto moderno, segundo Baudrillard (1993), configurou-se com base na relação de oposição entre modelo (entendido inicialmente como objeto único e, posteriormente, "personalizado") e série. Embora o autor afirme que não se possa associar modelo nem série aos objetos da sociedade pré-industrial, destaca que sua homogeneidade é percebida porque, em seu modo de produção, permanece o trabalho à mão, bem como sua função é menos especializada e o leque cultural das formas é menos vasto, havendo pouca referência às culturas anteriores ou externas. Contudo, na sociedade industrial, a segregação social foi maior. Os objetos industriais se massificam em prol da "democratização do acesso" e estimulam o consumo desenfreado. Os objetos ora se banalizam, ora se resignificam em seu valor; evoluem em séries e modelos, em um ciclo infindável e insustentável (BAUDRILLARD, 1993; MANZINI, 2008).

No design interno, esse esquema técnico, a que o termo design se refere, deve suceder um diálogo entre cliente e profissional que possibilite o máximo de tradução do ser no espaço em metro quadrado. Numa lógica capitalista globalizada significa inserir no espaço interno objetos que simbolizem signos que auto-refratem os proprietários ou parte das ideologias às quais se vinculam — o que inclui da lógica sustentável ao luxo. Pensar no design luxuoso, portanto, implica pensar em sua interface dialética de "personalização" versus processo excludente que gera e na alternativa possível de uma sustentabilidade sociocultural através de novos valores e comportamentos, novos modos de vida, individual e coletiva, local e global. E, sobretudo, a partir de uma nova percepção de bem-estar, a ser construída em corrente contrária à do modelo de consumo intrinsecamente insustentável, que se baseia na democratização do acesso a produtos e serviços que estavam (e ainda estão) acessíveis a pouco privilegiados (MANZINI, 2008).

Conforme lembra Ianni (1999, p. 119) a noção de aldeia global envolve "idéias, padrões e valores sócio-culturais, imaginários" que circulam em todo o planeta, ou seja: nossas ações reverberam nos demais, ainda que não estejam editadas no espaço midiático ou que sequer paremos para refletir sobre o problema, porque somos parte desta tribo que se pretende global a despeito de todas as suas idiossincrasias. 
Em âmbito global, segundo Manzini (2008, p. 39), a intenção comum do design, com vistas a um modelo de bem-estar sustentável, "é, ou deveria ser, criar as condições para que isso possa acontecer não como uma necessidade, mas como uma escolha”. Uma escolha individual e coletiva, resposta a uma "força de atração exercida pelas novas oportunidades e idéias de bem-estar, e não sob a pressão de eventos catastróficos”. A percepção do efeito boomerang, em que cada

melhoria tecnológica introduzida com a intenção de aumentar a ecoeficiência de produtos e serviços - por motivos enraizados na complexidade do sistema sociotecnológico como um todo - se transforma "naturalmente" em uma nova oportunidade de consumo, consequentemente aumentando a insustentabilidade dos sistemas nos quais foi introduzida.

A diminuição do peso ambiental expressa em produtos leves, menores, eficientes e econômicos não se mostrou suficiente para direcionar o sistema de produção e consumo à sustentabilidade. Corroborando com Manzini (2008, p. 45), reiteramos que "a relativa desmaterialização dos produtos não trouxe consigo nenhuma redução no consumo geral”.

Enquanto há peças do design que superam as cifras possíveis para a maior parcela da população mundial, grupos como os designers franceses que integram o projeto "Salvem a mobília" (no original, "Sauvez les meubles") reforçam a lógica sobre a necessidade de recuperar itens tidos como descartáveis (Bindo, 2009). A mesma lógica é defendida pelo grupo "Platform 21", em Amsterdã, cuja base ideológica está expressa no Repair Manifest (on-line), ou Manifesto do Reparo, em que o grupo indica 11 passos básicos para pensarmos e agirmos pela sustentabilidade do planeta e que resumimos a seguir:

1. Garantir vida longa aos produtos normalmente tidos como descartáveis; 2. comprar produtos que possam ser reparados e tenham peças disponíveis, para isso usar os direitos de consumidor, questionando antes de comprar; 3. entender que poder, no futuro, consertar o produto, não é sinônimo de troca após o desgaste do mesmo; 4. permitir a historicidade dos objetos a partir da sua preservação e longevidade; 5. ampliar a criatividade a partir dos reparos, com experimentos de novas técnicas, ferramentas e materiais; 6. lembrar que reparo não é styling, ou seja, dar aparência diferenciada para atrair o consumo, tornando produtos desgastados pelo uso em "apetecíveis", como registra Dorfles (1972); 7. consertar é fazer descobertas sobre os objetos; 8. recuperar coisas não se relaciona a economizar dinheiro, mas a uma concepção de vida; 9. recuperar transforma uma peça comum em algo único, que passa pela sua interferência; 10. recuperar nos devolve a independência como sujeitos, nos libera da escravidão tecnológica; 11. É possível recuperar qualquer coisa, até uma bolsa de 
plástico. Por fim, o slogan do grupo é provocador ao indicar: "Pare de reciclar. Comece a reparar" ("Stop recycling. Start Repairing”). A partir desta questão podemos indicar que no aspecto filosófico contemporâneo, ainda que tais questões pareçam recentes, estudiosos do problema como Rafael Cardoso aponta para a sua historicidade.

Ao contrário de outras áreas, nas quais a sustentabilidade e o impacto ambiental são discussões recentes, no design é uma preocupação que remonta há mais de meio século. Já nos anos 60, as sociedades de desenho industrial declararam o meio ambiente como questão central para o planejamento do design mundial. Em 1971, foi lançado um livro que influenciou toda uma geração de profissionais: Design for the Real World: Human Ecology and Social Change [Design para o mundo real: ecologia humana e mudança social], do designer Victor Papanek. Nele, o autor aborda a necessidade de levar baixa tecnologia para o terceiro mundo. Ele foi muito criticado, mas também incensado, ao propor, por exemplo, um televisor de 10 dólares, do tipo faça-você-mesmo. Outro filósofo e designer que contribuiu para essas reflexões é Buckminster Füller, com o Manual de Operação da Espaçonave Terra (1985), cujo mérito é a transmissão de conceitos acessíveis ao público em geral.

\section{INTEFACES DO DESIGN: LUXO E USO}

Ainda que historicamente o campo do design tenha essa preocupação com a sustentabilidade, o atrito ideológico é uma constante no campo, uma vez que ao trabalhar com desejos, o usuário desconectado com questões coletivas, pode priorizar aspectos meramente luxuosos. A concepção de um projeto de interiores permeia o plano imaginário e reflete a liberação dos desejos e anseios das pessoas. A materialização da ideia acontece com a existência de um espaço resguardado para receber os materiais responsáveis pela composição do lugar. Para Augé (1994, p. 52), os lugares possuem pelo menos três características: “eles se pretendem (pretendem-nos) identitários, relacionais e históricos”. Por isso a importância dos materiais como elemento representativo da identidade.

Em interiores, os materiais e objetos são escolhidos por diferentes características e aplicações, possibilitando o exercício de atividades no ambiente. A função, a estética, incluindo o material de confecção, as cores, formas e acabamentos são elementos fundamentais para acontecimento dessa escolha. Entretanto, um aspecto, algumas vezes 
menos explícito, mas não menos importante, corresponde à carga simbólica que um objeto ou um material pode trazer ao lugar. Bürdek (2006, p. 322) explica o símbolo como sendo

\begin{abstract}
um sinal que por meio de uma combinação (convenção) possui significado intercultural. Sua função como sinal ou figura simbólica o símbolo adquire na medida em que representa algo que não seja perceptível. Estes símbolos são encontrados na religião, na arte e na literatura, mas também nas ciências naturais, na lógica e na filosofia da língua e na variedade da vida diária: o significado dos símbolos se dá muitas vezes de forma associativa e eles não são determinados de forma clara: sua interpretação é dependente de cada contexto.
\end{abstract}

A simbologia de um objeto de luxo está vinculada à representação de status, que podemos traduzir como ideia de pertencimento. Possuir um produto de uma determinada marca significa não só prosperidade, mas integração a um grupo social considerado importante para o sujeito (De Moraes, 1999). Desta forma, é possível afirmar que os produtos possibilitam integração social, visto que o seu uso por um grupo de pessoas demonstra a existência de afinidades entre elas (Bürdek, 2006). Com isso, destacamos duas questões: o ter para pertencer e o pertencer por ter.

A tipologia do material também é um elemento representativo de pertencimento social. Muita dessa carga figurativa é criada e condicionada pelo contexto sócio-cultural do lugar. Utilizar materiais considerados nobres pela sociedade como mármores e granitos para revestir pisos e paredes exemplifica essa concepção. A situação torna-se ainda mais significativa quando são utilizados materiais raros e de custo elevado, como o conhecido Mármore Carrara, de origem italiana. Essa simbologia pode importar a ponto de Ilustração 1 - Cadeira Vermelha. Fonte: Bürdek 2006:197. profissionais da área não especificarem

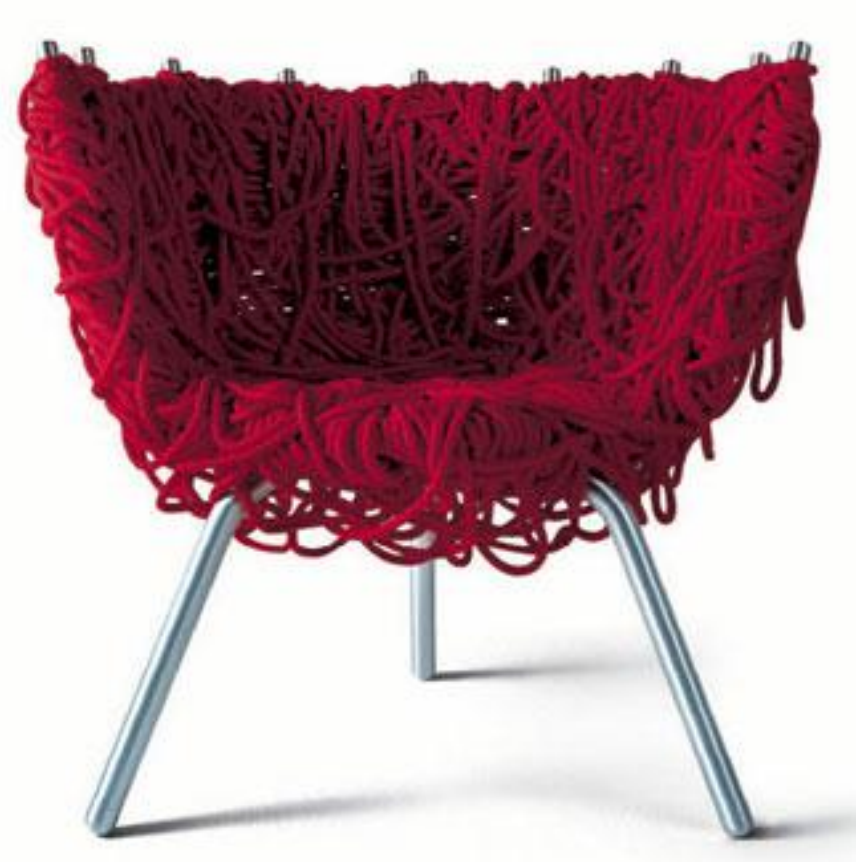
produtos com aspecto visual semelhante, sob alegação de rejeitar cópias. Com isso alguns materiais são discriminados e podem ter sua vida útil de fabricação reduzida. Há também outra questão em tela: a exploração do produto diante do impacto ambiental que pode gerar.

Um artigo considerado de luxo é aquele desejado por grande parte da população, mas acessível a poucos devido ao seu alto valor de mercado. 
Peças mais elaboradas, com formas diferenciadas ou com grande apelo mercadológico, além do conceito aplicado, podem ser ícones referenciais. Essas peças adquirem uma identidade própria, tornando-se objeto de desejo. Ter uma cadeira Vermelha dos irmãos Campana reflete modernidade e status (Ilustração 1). A cadeira Aeron criada por Don Chadwick e Bill Stumpf e utilizada por celebridades representa luxo, riqueza e poder (Ilustração 2). O espremedor de laranja de Philippe Starck consiste num importante exemplar de objeto de desejo (Ilustração 3). Criado em 1990 com forma considerada inusitada, é um produto que

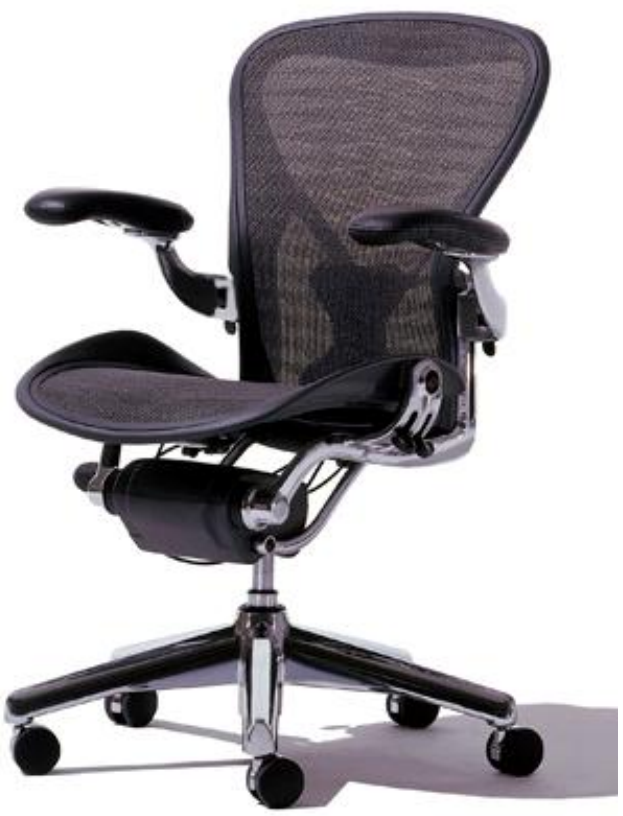

Ilustração 2 - Aeron Chair deixou de exercer a sua função primária, fazer sucos, para receber uma nova, decorar ambientes (De Moraes, 1999). Adquirir produtos de desejo nem sempre é meta alcançada, criando-se um conflito entre o ser, ou seja, a identidade e o poder, que é a capacidade financeira do indivíduo.

O anseio de aceitação social e a vaidade mediante a necessidade de elogios podem interferir na concepção de um projeto de interiores, criando um ambiente totalmente impessoal e estranho aos proprietários. Bittencourt (2007) exemplificou essa situação com o seguinte caso: uma cliente contratou uma profissional para elaboração de um projeto de interiores em seu apartamento recém-construído. O projeto foi aceito e executado. $\mathrm{O}$ ambiente agradou tanto que a proprietária enumerou cada peça decorativa nos respectivos lugares para que ao limpar fossem devidamente recolocados. Uma empregada, responsável por cobrir as férias da titular e não familiarizada com a questão, apagou todos os números que indicavam o lugar das peças decorativas. Passado o desespero, a cliente telefonou para a mesma profissional contratando-a para recolocar as peças (Bittencourt, 2007, p. 169). Dessa forma, percebe-se que a proprietária abdica de imprimir sua marca pessoal e personalidade no ambiente em detrimento a um ambiente impessoal, mas que tem aceitação dos visitantes.

Todas essas questões nos permitem refletir sobre o tipo de sociedade na qual o designer precisa atuar e na qual ele precisa dominar conceitos que podem comprometer a concepção "original” de um objeto, de um ambiente. A função social do designer, em nossa compreensão, extrapola a ideia inicial para a qual foi criada: projetar, idealizar, pois as 
marcas do futuro já se pronunciam nas ideias contemporâneas. Essa é a razão pela qual estudiosos do campo centram seu foco, neste início de século XXI, em estudos que possam refletir futuramente um compromisso com o meio ambiente e com as pessoas que habitarão o planeta. E, ainda em estudos que favoreçam as relações humanas, as interações com os objetos e os espaços de forma saudável e acessível a todos.

\section{USO E CONSUMO SUSTENTÁVEL DE BENS DE LUXO}

Pensar em design requer, necessariamente, refletir sobre conceitos vitais para o capitalismo, como uso e consumo. Nos apoiamos em Sennet (2006) para indicar que o capitalismo contemporâneo ganha feição cada vez mais "impaciente" e com cobranças de resultado a curto prazo. Essa pressão por resultados céleres, de qualquer modo, já pode ser encontrada em autores que refletiram sobre o design na década de 60 dos anos XX, como Papanek (2006), no momento em que pensa criticamente sobre o seu primeiro emprego e discute a responsabilidade social e moral desta profissão controlada, no âmago do seu habitus, pelo capital.

A proposta de Sennet (2006) requer que, para pensarmos em mercadorias, igualmente pensemos na mudança que ocorre sobre bens de consumo ao longo dos anos. O problema dessa análise, a nosso ver, é que o fetiche marxiano borrado por Sennet no produto

Ilustração 3 - Espremedor de laranja

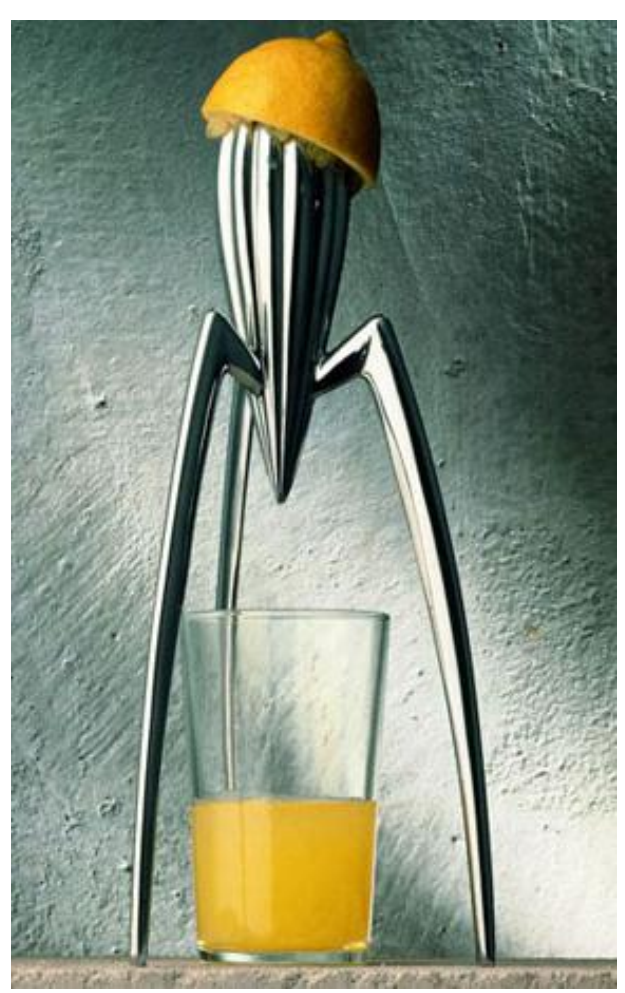

vulgarizado pela globalização continua reforçado quando pensamos em bens de luxo, ainda que tragam marcas da indústria, e não do artesão, pois possuem uma marca de seletividade a partir do momento em que são produzidos em baixa escala. Já está em Ribeiro (1981) exausta discussão sobre a importância da evolução tecnológica como fundamental para o processo civilizatório e no qual o autor indica a possibilidade de outras forças, além das hegemônicas, de ter a possibilidade de produzir inovação, desde que consideramos tanto a lógica global como as locais.

No entanto, essa análise não invalida a lógica de Bourdieu (2010, on-line) quando pensa as classes dominantes como as produtoras dos bens simbólicos 
que terminam por reforçar a legitimidade da sua dominação. Ainda que Bourdieu tenha centrado, ao longo das suas pesquisas, sua atenção sobre bens simbólicos midiáticos, com maior fôlego, o seu conceito de habitus também é útil para pensarmos a prática do design de interiores, uma vez que tratamos também de conjunto de relações históricas internalizadas no/pelo sujeito (BOURDIEU, 1997; GUTIÉRREZ, 1994).

Propomos uma (re)visão do uso e do consumo de bens de luxo sob a ótica da sustentabilidade ao retomarmos o exemplo do espremedor de cítricos “Juicy Salif”, do designer francês Philippe Starck, escolhido para ilustrar a capa da edição brasileira (Ilustração 4) do livro Design Emocional: por que adoramos (ou detestamos) os objetos do dia-a-dia,

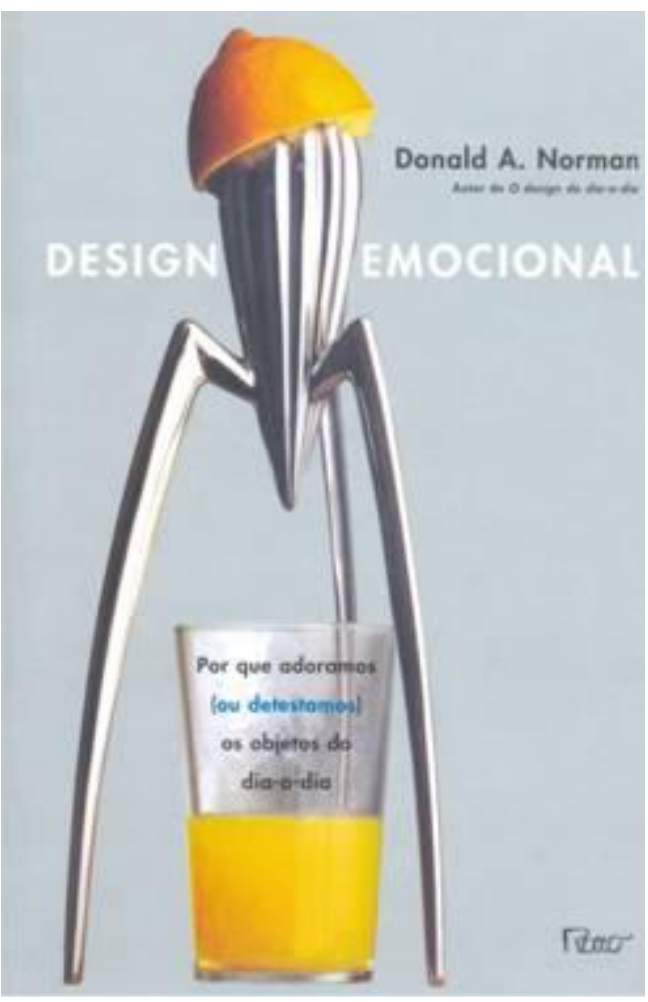

Ilustração 1 - Capa do livro Design Emocional. de Donald A. Norman (2008).

Damazio \& Mont'alvão, no prefácio deste livro (Norman, 2008, p. 18), destacam que

\begin{abstract}
somos todos designers quando reorganizamos objetos e móveis em nossas casas, quando escolhemos o livro que queremos ler, quando os decidimos por este ou aquele sapato e transformamos coisas e espaços em nossas próprias coisas e espaços. [...]. Embora não tenhamos controle sobre o design dos muitos objetos que compramos, somos livres para escolher o que usamos e como, onde, com quem e quando usamos.
\end{abstract}

Ao deixar de exercer a função prática de fazer sucos e assumir a função de signo do design como objeto de adorno em projetos de interiores, o espremedor de frutas transita no universo do luxo como objeto de uso, do desejo ou de ambos? O que motiva o seu consumo ou a sua aquisição? O que significa tê-lo? Para quê ou para quem? Sem dúvida, a sua forma seduz os olhos de quem o vê e o percebe, exerce uma atração inicial que instiga seu observador à compra, conforme descreve Norman (2008, p. 137):

O espremedor era realmente sedutor. Eu o vi e, imediatamente, passei pela seqüência de respostas tão adoradas por comerciantes: 'Uau, eu quero', disse para mim mesmo. Só então perguntei: 'O que é? Para que serve? Quanto custa?', concluindo com: 'Vou comprar', o que fiz. Essa foi uma pura reação visceral. O espremedor é de fato bizarro, mas adorável. 
Alberto Alessi (apud Norman 2008, p. 137) descreve o primeiro passo do processo de design da peça, ocorrido em uma pizzaria em Capraia, na ilha Toscana, Itália.

\begin{abstract}
No guardanapo, [...], havia alguns esboços. Esboços de lulas. Eles começavam do lado esquerdo e, à medida que iam avançando para o direito, assumiam a forma inconfundível do que se tornaria o mais celebrado espremedor de frutas cítricas do século que acabou de chegar ao fim. Vocês podem imaginar o que aconteceu: enquanto comia um prato de lulas e espremia um limão em cima dele, nosso homem [o designer] recebeu sua inspiração! O Juicy Salif nasceu, e com ele algumas dores de cabeça para os defensores de 'A forma segue a função'.
\end{abstract}

Nesse caso específico, as funções determinaram a forma. Contudo, a materialização do produto enquanto objeto de uso não seguiu esse propósito. Pelo contrário, resultado de uma fase "over-design" do projetista nas décadas de 80-90, a peça é analisada por Khaslavsky e Shedroff (apud Norman, 2008), sob vários aspectos, dos quais recortamos: a. atrativa e divertida, porque difere de qualquer outro utensílio de cozinha por sua aparência e materiais (banhada a ouro); b. surpreendente, por não ser imediatamente identificada como um espremedor de frutas, sendo incomum e intrigante em face de sua verdadeira função; c. excede as expectativas e necessidades óbvias, mostrando-se algo inteiramente diferente; $d$. associa valores ou vínculos com metas pessoais, quando transforma a rotina de espremer uma laranja numa experiência especial, inovadora, simples e elegante em forma e desempenho, além de valorizar a ação e o desejo de possuir não o objeto, mas todas as qualidades a ele associadas e que o criaram - inovação, originalidade, elegância e sofisticação [o próprio luxo]; e. promete e cumpre todas as metas e promessas, tornando extraordinária uma ação ordinária (fazer sucos), bem como não a ensina, porém ensina ao usuário que objetos cotidianos mostram-se interessantes e o seu design pode enriquecer e significar a vida.

Nesse contexto, voltamos ao cerne da nossa apropriação dos objetos como signos do design, ora para o uso, tomando-se por referência a sua função prática-operativa e seu desempenho efetivo, ora para o mero consumo subjetivo "do ter, do possuir" como forma de enquadramento social, apropriando-se da sua referência simbólica e emocional, que pode ou não estar vinculada ao seu bom design. Isso ocorre, segundo Norman (2008), quando há um imbricamento entre o design e as relações de uso e consumo dos objetos - que gostamos ou detestamos —, tendo os três níveis de design emocional como os seus principais balizadores, intermediados por uma ação consciente ou inconsciente. "Visceral, comportamental e reflexiva: essas três dimensões muito diferentes estão sempre entrelaçadas em qualquer design. Não é possível ter design sem todas as três” (Norman 2008, p. 6). 
Signos do Design de Interiores: interfaces entre uso, consumo e arte

de Miquelina Cavalcante, Rossana Gaia, Patrícia Lins e Áurea Rapôso

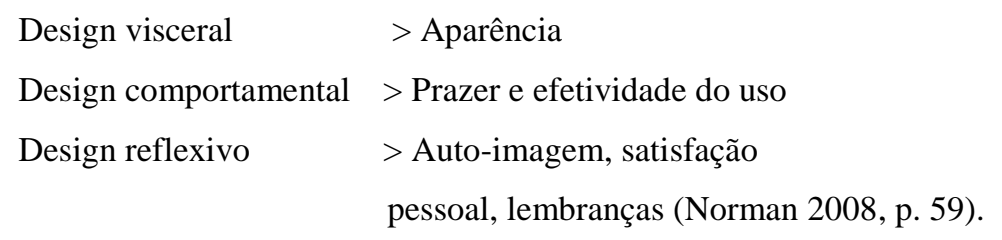

O mais importante em torno desses três elementos é que eles combinam emoção e cognição. Podemos afirmar que o sensorial e o racional, normalmente vistos como antagônicos, a partir da interpretação de Norman (2008), assumem a posição de dois conceitos inseparáveis e que, embora não seja explícita (na maioria das vezes, ocorre de forma inconsciente), em toda ação ou pensamento lógico e racional reside emoção. Enquanto ação de concepção e planejamento de algo novo, (in)existente e (i)material, o design une de modo sistemático emoção e cognição em seu fazer.

Cabe-nos perguntar: como a sustentabilidade se associa ao design emocional no tocante ao uso e consumo dos produtos, sobretudo os de luxo? O elo reside no design comportamental, que proporciona simultaneamente o prazer e a efetividade do uso, que restabelece uma relação objeto-tempo, em um ciclo dirigido pelo usuário-sujeito. Para que o prazer seja eterno, os objetos de luxo devem apresentar vida útil extensa, sendo bens mais duráveis. E para garantir vida longa ao prazer "dois componentes são exigidos: a habilidade do designer de oferecer uma experiência intensa e rica, e a habilidade daquele que a percebe" (Norman, 2008, p. 135). Papanek (1995, p. 9), ao destacar o repertório de capacidades e talentos de um designer, inclui tanto a habilidade de combinar a resolução técnica da forma criada aos fatores sociais e estéticos quanto a sabedoria de prever os impactos econômicos, políticos e ambientais. $\mathrm{O}$ autor abre a sua discussão sobre o poder do design, questionandonos:

TODO O DESIGN está vocacionado para um objectivo. Somente as nossas perguntas mudam. Já nos inquirimos: 'Como é que fica?' ou 'Como funciona?'. Agora estamos mais interessados na resposta a: 'Como se relaciona?'

O estudo das relações entre objetos, uso e consumo é um dos objetivos do design sustentável, na perspectiva do que é mais durável ao longo do tempo. Nesse sentido, tanto criadores quanto consumidores (ambos usuários e co-agentes sociais) estabelecem relações lógicas e emocionais com os objetos de design. Ambos experimentam sensações de prazer e/ou seduções como vivenciam situações de práxis e/ou usabilidade no dia-a-dia. Trata-se do 
prazer do aprendizado social/coletivo ou pessoal/individual ("personalizado"), através da experimentação, que busca trazer significado e padrão aos objetos.

Para Papanek (1995), o ideal era que não precisasse existir a categoria design sustentável, porque a sustentabilidade revela-se um princípio intrínseco à prática de design. Conceber, para quê? Para quem? E, para quando? Ou, por quanto tempo? Todo objeto produzido, projetado, adquirido, apropriado deve ser durável.

Parece que, ao concentrarmo-nos em bens que não duram tanto quanto esperamos e que se estragam, perdemos o nosso sentido de qualidade e do transitório. Ao tentarmos tornar a arte lucrativa e útil, perdemos também a nossa sensação de alegria. Ao promovermos as produções triviais do pós-modernismo e do desconstrutivismo, e ao considerá-las dignas de sérios debates, abandonámos a felicidade (Papanek 1995, p. 15).

Ao contrário do que se pensa, conforme defende Manzini (2008), o caminho social para a sustentabilidade "é o contrário da conservação" e nos explica que preservar e regenerar o nosso capital social significa "justamente romper com as tendências dominantes em termos de estilo de vida, produção e consumo, criando e experimentando novas possibilidades".

Nesse contexto, permitamos a Philippe Starck a sua própria crítica e defesa. Em entrevista a Martins (2009), o designer francês relembrou que, há pouco mais de dez anos, foi produtor de materialidade "luxuosa, descartável" e que se envergonha disso. E destaca: “O mundo caminha para a imaterialidade. Pode ver pelos computadores, que vêm diminuindo de tamanho e, em breve, podem estar dentro do nosso corpo". Não satisfeito, ressalta: "Tudo o que fiz até certo ponto é absolutamente desnecessário. Design não é necessário, é algo vazio. Demorei todos estes anos talvez para perceber isso. Seres Humanos precisam de amor. E de humor" (Starck apud Martins, 2009, p. 67). E acrescenta:

Mexo com os dois extremos, de um megaiate de US\$ 200 milhões a uma mamadeira de US\$ 2. Antigamente, ser designer era fazer coisas bonitas, que quase ninguém podia comprar. Hoje pode ser um trabalho político (apud Martins 2009, p. 68).

Atualmente, Philippe Starck (apud Martins, 2009, p. 68) diz trabalhar para fazer as coisas baratas, através da "estratégia de Robin Hood", que "consiste em trabalhar com projetos muito sofisticados e caros, com gente inteligente e rica. E depois aplicar o que se aprende tentando atender o maior número de pessoas, a preço acessível e com fácil uso". Em consequência, indica novos parâmetros para a sua atividade. 
custar em torno de US\$ 650. 'Quero atingir milhões com esse produto. Passei 30 anos numa luta política para democratizar o design. O próximo passo é a energia democrática. Depois virão barcos a hidrogênio e com energia solar', anuncia. (apud Martins 2009, p. 68).

Para Papanek (1995, p. 15), quando "tudo é transitório, é a vida que se torna duradoura". E, diante do impasse ou da interface entre uso, consumo e arte - cabe ao designer escolher -, o que temos a nos perguntar: qual o impacto do meu trabalho sobre o ambiente? E, ainda, qual o contributo que tenho a dar para criar um futuro viável, uma sociedade de consumo sustentável de bens usáveis e duráveis?

\section{CONCLUSÕES POSSÍVEIS}

O uso do espaço e dos objetos, considerados ou não objetos de design, comunicam sobre o ser humano que está inserido nessa relação com respectivas interferências.

Autores como Baudrillard (2008) nos permitem repensar não somente sobre o próprio ato de consumo em si, mas também na forma como a sociabilidade na qual nos inserimos nos estimula a consumir para adequarmos a imagem que temos do nosso eu frente à imagem que os grupos com os quais convivemos esperam de nós e que pode ser traduzida como status, ou seja, a forma pela qual somos classificados perante um grupo ou grupos e que nos concede privilégios, mas também obrigações e limites. É o desejo de consumir, sem reflexão sobre as necessidades reais (de nós mesmos e das demais pessoas que habitam nosso planeta), que incrementa e sustenta a lógica capitalista, na qual o design insere-se como um dos mais significativos signos.

A sociedade na qual estamos inseridos nos faz esquecer a racionalidade e nos faz agir de modo visceral e, sem pensar, compramos para pertencer, para ser percebido. É uma constante necessidade de ser notado, chamar atenção, como criança que fica o tempo todo chamando os pais para ser percebida e se sentir protegida. Repensar nossos usos, a reutilização de nossos objetos, repensar nossas práticas deve nos levar a um caminho da essencialidade, da busca constante do ser significante.

Pensar o design para um mundo tangível, conforme nos ensina Papanek (2006), exige atenção do(a) profissional tanto para o que projeta quanto para o que desenha. Além disso, no caso do design de interiores, o rigor deve existir também na hora de sugerir materiais e equipamentos para o ambiente. O designer atua na gestão dos objetos ambientes que devem ser físicos e espaciais, mas também simbólicos e cognitivos no sentido de auto-refratarem a essencialidade e não o que é transitório. 
Ao invés de seguirmos a ditadura da moda, vigente em todas as áreas, mas exacerbada no design em todas as suas ramificações, exige romper com a lógica do "vale-se quanto paga-se", ou seja, com a ideia do luxo associado ao alto custo - que inclui na conta o consumo dos recursos naturais do planeta e os inevitáveis desastres ecológicos. Traduzir esta emblemática questão no design significa que aos profissionais do campo são vitais as responsabilidades social, ambiental e moral. Esta atitude ética, do nosso ponto de vista, só é possível com o domínio da lógica técnica e tecnológica e com a sensatez da estética durável, de ciclo longo, sobretudo para os objetos ambientes.

Nossa reflexão, portanto, requer, como nos indica Ono (2006, p. 100), entender a sintonia entre o design e a cultura no desenvolvimento de artefatos para uma sociedade. Em outras palavras: consideramos a pluralidade e a variabilidade de significados dos artefatos para os indivíduos e grupos sociais e as inter-relações contextuais. Designer e organizações produtivas precisam urgentemente perceber as pessoas ao longo de todo o desenvolvimento de produtos, "suas características e necessidades fundamentais, e não [vê-las] como meros elementos mercadológicos atrelados a estereótipos e estratégias para a promoção do consumismo desenfreado". Desconstruir e reinterpretar significados, criar referências e realidades, é tônico essencial à diversidade e à dinâmica da vida.

Nesse contexto, o uso do conceito de habitus, na atividade do design de interiores, é útil para pensarmos que a ética profissional não se opõe à prática laboral. Portanto projetar um ambiente interno, um produto, um livro ou um endereço virtual, na perspectiva bourdieuniana implica pensar nos princípios explicativos de sua composição, uma vez que este profissional está inserido em uma lógica que inclui estilo de vida e comunicação (BOURDIEU, 1983, 2001).

O capital cultural acumulado ao longo dos anos pelo designer permite que ele transite entre saberes que tanto podem reforçar a hegemonia, quanto, numa lógica que segue a perspectiva de Ribeiro (1979), indicar alternativas que reforcem a importância das classes populares. Para que isto ocorra, entendemos ser relevante a formação crítica do profissional, a partir do diálogo do campo do design com outros saberes legitimados, como a comunicação, a sociologia e a psicologia. Essas questões, longe de estarem encerradas, apresentam-se como campo aberto para futuras investigações epistemológicas e práticas.

\section{REFERÊNCIAS BIBLIOGRÁFICAS}


ARNHEIM, R. Arte e Percepção Visual: Uma Psicologia da Visão Criadora. 6. ed. São Paulo: Livraria Pioneira Editora, 1991.

AUGÉ, M. Não-lugares: Introdução a uma antropologia da supermodernidade. São Paulo: Papirus, 1994.

BAUDRILLARD, J. A sociedade de consumo. 3a . ed. Lisboa: Edições 70, 2008.

BAUDRILLARD, J. O sistema dos objetos. São Paulo: Perspectiva, 1993.

BIGAL, S. O design e o desenho industrial. São Paulo: Annablume, 2001.

BITTENCOURT, L. "Meu, Dele ou de Outros? Especulações sobre o desejo no projeto arquitetônico", in LEITÃO, L. \& AMORIM, L. (orgs.). A Casa Nossa de Cada Dia. Recife: Ed. Universitária da UFPE, 2007.

BOURDIEU, P. Questões de Sociologia. Rio de Janeiro: Marco Zero, 1983.

BOURDIEU, P. Sobre a televisão. Rio de Janeiro: Jorge Zahar, 1997.

BOURDIEU, P. A Gênese dos conceitos de habitus e campo. In: BOURDIEU, P. O poder simbólico: Rio de Janeiro: Bertrand Brasil, 2001. p. 59-74.

BOURDIEU, P. Sobre el poder simbólico. Disponível em: <http://sociologiac.net/biblio/Bourdieu_SobrePoderSimbolico.pdf $>$. Acesso em: 05.abr.2010.

BÜRDEK, B. História, teoria e Prática do Design de Produtos. São Paulo: Edgar Blücher, 2006.

BINDO, M. "Reforma é cool”, in Revista Vida Simples, Ano 7, edição 79, n’. 5. São Paulo: abril, mai. 2009. p. 14.

DAMAZIO, V. \& MONT'ALVÃO, C. "Prefácio à Edição Brasileira”, in NORMAN, D. A. Design emocional: por que adoramos (ou detestamos) os objetos do dia-a-dia. Trad. Ana Deiró. Rio de Janeiro: Rocco, 2008.

DE MORAES, D. Limites do Design. 2a . ed. São Paulo: Studio Nobel, 1999.

DORFLES, G. “Aspectos positivos e negativos do styling”, in DORFLES, G. Introdução ao design industrial: linguagem e história da produção em série. Lisboa: Edições 70, 1972. 
FIOCHI, M. A. “Una cosa mentale: Em entrevista, Rafael Cardoso fala sobre a desmaterialização do design", in Itaú Cultural. Disponível em: <http://www.itaucultural.org.br/index.cfm?cd_pagina=2720\&cd_materia=450>. Acesso em: 09.06.2009.

FLUSSER, V. O mundo codificado: por uma filosofia do design e da comunicação. São Paulo: Cosac Naify, 2007.

FÜLLER, B. Manual de Operação da Espaçonave Terra. Brasília: Editora da UnB, 1985.

GUTIÉRREZ, A. B. Pierre Bourdieu: las prácticas sociales. Buenos Aires: Centro Editor de América Latina, 1994.

KEY, A. A funcionalidade no design contemporâneo. In: MOURA, Mônica (org.). Faces do design 2: Ensaios sobre arte, cultura visual, design gráfico e novas mídias. São Paulo: Edições Rosari, 2009, p. 17-24.

IANNI, O. Teorias da Globalização. 5a . ed. Rio de Janeiro: Civilização Brasileira, 1999.

LIMA, F. "Não basta reciclar. A onda agora é consertar" in Blog do Planeta, Revista Época, 7.mar.2009. Disponível em:

<http://colunas.epoca.globo.com/planeta/2009/03/07/pare-de-reciclar-a-onda-agorae-consertar/>. Acesso em: 24.abr.2009.

MANZINI, Ézio. Design para a inovação social e sustentabilidade: comunidades criativas, organizações colaborativas e novas redes projetuais. Trad. Carla Cipolla (coord.). Rio de Janeiro: E-papers, 2008. (Cadernos do Grupo de Altos Estudos; v.1).

MARTINS, M. Espelho, espelho meu - mirror, mirror on the wall. In: Revista TAM. Nas Nuvens. Paixão pelo Rio. Ano 02. No 15. São Paulo: Virtú Editora e Produtora Ltda., março 2009.

NORMAN, D. A. Design emocional: por que adoramos (ou detestamos) os objetos do diaa-dia. Trad. Ana Deiró. Rio de Janeiro: Rocco, 2008.

ONO, Maristela Mitsuko. Design e cultura: sintonia essencial. Curitiba: Edição da Autora, 2006.

PAPANEK, V. Design for the real world: Human ecology and social change. 2nd edition. London: Thames \& Hudson, 2006.

PAPANEK, V. Arquitetura e Design. Ecologia e Ética. Lisboa: Edições 70, 1995. 
Signos do Design de Interiores: interfaces entre uso, consumo e arte

de Miquelina Cavalcante, Rossana Gaia, Patrícia Lins e Áurea Rapôso

REPAIR MANIFEST in: "Platform 21". Disponível em:

<http://www.platform21.nl/index.php?lang=en >. Acesso em: 24.abr.2009.

RIBEIRO, D. O processo civilizatório: Estudos da Antropologia da Civilização. $6^{\mathrm{a}}$. ed. petrópolis: Vozes, 1981.

SANTOS, M. R. "Design e Cultura: os artefatos como mediadores de valores e práticas sociais”, in QUELUZ, M. L. P. Design \& Cultura. Curitiba: Editora Sol, 2005, p.1332.

ZEVI, B. Saber ver a arquitetura. São Paulo: Martins Fontes, 1978.

Artigo recebido em 27/7/2009.

Aprovado em 22/3/2010. 